\title{
DESENVOLVIMENTO DE MATERIAIS RESISTENTES AO DESGASTE E À CORROSÃO A QUENTE APLICADOS EM GRELHAS DE SINTERIZAÇÃO*
}

\author{
Ivênio de Oliveira Teixeira ${ }^{1}$ \\ Eduardo Albertin ${ }^{2}$ \\ Fabrício Candido Marques ${ }^{3}$
}

\section{Resumo}

Grelhas constituem o fundo móvel dos setores da esteira sem fim das máquinas de sinterização. Diferentes tipos de materiais têm sido utilizados para a fabricação dessas peças, desde aços resistentes ao calor e inoxidáveis até ferros fundidos de alta resistência, tendo como parâmetro de controle a perda de massa ou redução da espessura das grelhas. A necessidade do aumento do ritmo operacional das sinterizações ao longo dos anos tem levado ao aumento da substituição de grelhas, contrapondo ao aumento da produtividade das sinterizações. Desta forma, a adequação da resistência ao desgaste abrasivo e a minimização de transformações microestruturais em função as condições de utilização dos materiais desses componentes mecânicos têm sido alvo do desenvolvimento de materiais para essa aplicação. Nesse trabalho é discutido o desenvolvimento de materiais aplicados em grelhas de sinterização, visando o aumento da sua vida útil, a partir do melhor entendimento dos mecanismos de degradação e da realização de ensaios laboratoriais de desgaste abrasivo, corrosão a quente e fadiga térmica. Dentre cinco alternativas avaliadas, a concepção de material com matriz ferrítica e adição de elementos químicos formadores de carbonetos mais estáveis a elevadas temperaturas e formação de camada mais aderente de óxidos apresentou melhores resultados, gerando uma perspectiva de aumento da vida útil da ordem de pelo menos três vezes em relação à condição atual.

Palavras-chave: Grelha de sinterização; Ferro fundido de alto cromo.

\section{DEVELOPMENT OF WEAR AND HOT CORROSION RESISTANT MATERIALS APPLIED TO SINTERING GRATES}

\begin{abstract}
Grates are mobile background parts used in sectors of sintering machine strands. Various materials have been used in the manufacture of such parts ranging from heat resistant and stainless steels to high chrome cast iron. Their control parameter in service is either the weight loss or thickness reduction of the grates. The need to increase the operating output of sintering over the years has increased the replacement of grates, impairing sintering productivity. Thus, the suitability of abrasive wear resistance and the minimization of microstructural change in service of the mechanical components from these materials have been the target in the development of materials for such applications. The development of materials used in sintering grates is discussed in this paper, aiming to increase their useful life, based on laboratory tests involving abrasive wear, hot corrosion and thermal fatigue in five alternative alloys. Among the alloys evaluated, the material with ferritic matrix alloyed with elements that forms stable carbides at elevated temperatures and thinner corrosion product layer showed better results. This led to a perspective of increasing the useful life around three times the life in the current condition.

Keywords: Sintering grate; High chromium cast iron.

Engenheiro mecânico, Msc., Usiminas - Centro de Pesquisa e Desenvolvimento, MG, Brasil.

Engenheiro metalurgista, Dr., IPT-Instituto de Pesquisas Tecnológicas, SP, Brasil.

Técnico metalurgista, Usiminas - Centro de Pesquisa e Desenvolvimento, MG, Brasil.
\end{abstract}




\section{INTRODUÇÃO}

A sinterização é um processo de aglomeração a quente de uma mistura de finos de minérios, coque, fundentes e adições, com dosagens e composições químicas definidas, cujo produto resultante, o sínter, apresenta características químicas, físicas e metalúrgicas compatíveis com as solicitações do alto-forno. Um dos equipamentos principais de uma unidade de sinterização contínua é a máquina de sínter propriamente dita, a qual consiste, fundamentalmente, de uma esteira sem fim composta de grelhas. As grelhas suportam a mistura a sinterizar, permitindo a passagem entre elas do fluxo de ar. Além desse componente, a unidade de sinterização é composta de sistemas de aglomeração a frio, exaustão, resfriamento do sínter e de beneficiamento e classificação do produto final, conforme mostrado na figura 1.

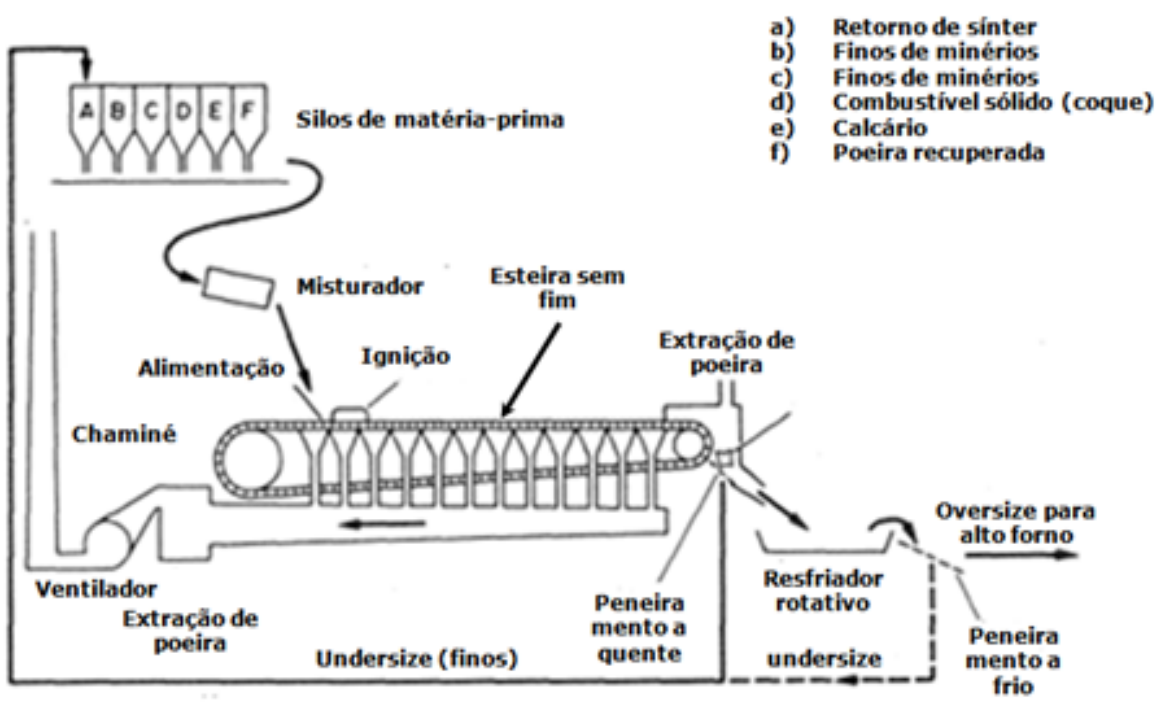

Figura 1. Planta esquemática de sinterização contínua [1].

A formação da camada de mistura a sinterizar acontece na região de alimentação, após a mistura e aglomeração das matérias-primas. No momento da alimentação dessa mistura sobre a esteira sem fim, preliminarmente, adiciona-se um forro de sínter com granulometria controlada, denominada de bedding. Ao longo do processo de sinterização, a esteira se movimenta desde a região de carregamento da mistura a sinterizar até a descarga do sínter, expondo as grelhas a temperaturas entre $150^{\circ} \mathrm{C}$ e $800^{\circ} \mathrm{C}$. Os gases de combustão formam uma atmosfera oxidante e redutora, potencialmente corrosiva, durante o movimento da esteira. No ponto de inversão dessa esteira acontece a queda por gravidade do sínter sobre o britador primário, com intenso desgaste abrasivo dessas peças. A partir daí, as grelhas sofrem resfriamento por exposição ao ar até a posição de carregamento. O tempo de exposição das grelhas ao calor e ao resfriamento em atmosfera ambiente dependerá da velocidade e da extensão da esteira.

$\mathrm{O}$ aumento do consumo de grelhas na Usiminas tem sido percebido nos últimos anos em função da ocorrência de empenos, quebra e de perda de massa. Em observações preliminares, foram identificadas condições operacionais do processo de sinterização que foram alteradas em relação à prática que normalmente se adotava, visando ao aumento de produtividade das máquinas. Este fato favoreceu a maior exposição das grelhas ao calor, principalmente, pelo aumento da velocidade do processo e pela alteração da característica da carga do sínter, como, por 
exemplo, aumento da proporção de combustível sólido. A degradação das grelhas, então, poderia ser associada à incompatibilidade do material atual utilizado com as condições operacionais atuais. Recentemente, alternativas de projeto de ligas para grelhas de sinterização foram propostas na Usiminas, visando aumentar a vida útil dessas peças. Espera-se, com isso, a diminuição das paradas operacionais para troca de grelhas ou setores de grelhas e, por conseguinte, o aumento da produtividade das máquinas de sinterização das usinas de Ipatinga e de Cubatão.

Historicamente, as grelhas de sinterização têm sido fabricadas de aços inoxidáveis austeníticos e ferríticos ou de ferros fundidos de alto teor de cromo. A utilização de ferros fundidos de alto teor de cromo em grelhas de sinterização é preferida em função da maior resistência ao desgaste à abrasão desses materiais [2;3].

A composição química do material das grelhas afeta diretamente os mecanismos de desgaste abrasivo e as transformações microestruturais. Desta forma, a definição da composição química do material a ser utilizado nas grelhas de sinterização, basicamente, deve levar em consideração a resistência ao desgaste tribológico, a resistência aos mecanismos de degradação química e a resistência à fadiga térmica [2; 3].

A resistência ao desgaste tribológico é diretamente proporcional ao teor de carbono e às características dos carbonetos. Por exemplo, em ligas hipereutéticas, a formação de carbonetos pró-eutéticos grosseiros do $\mathrm{M}_{7} \mathrm{C}_{3}$ favorece a propagação de trincas e diminui a resistência desse material às solicitações mecânicas. No caso de ligas hipoeutéticas, a matriz metálica formada na solidificação é de austenita. Entretanto, neste tipo de material pode ocorrer a formação parcial de ferrita na solidificação, diminuindo, assim, a sua resistência à abrasão [4].

A adição de cromo em ligas do sistema Fe-C propicia um efeito sinergético de endurecimento estrutural e de estabilidade química sob condições de elevadas temperaturas, quando o teor desse elemento químico na matriz ultrapassa o valor de $12 \%$, além de favorecer a formação de carbonetos eutéticos mais resistentes. Com teor de cromo em torno de $30 \%$ e utilizadas em temperaturas em torno de $700^{\circ} \mathrm{C}$, as grelhas de ferro fundido de alto cromo tendem a apresentar menor condutividade térmica, apesar de sua excelente resistência à corrosão. Por isso, menores teores de $\mathrm{C}$ e $\mathrm{Cr}$ neste tipo de liga propicia melhor desempenho sob fadiga térmica, resultando, assim, em menores gradientes térmicos e de tensões [5;6].

A estabilidade química dos carbonetos de ferro fundido branco pode ser melhorada quando são adicionados elementos químicos como Mo e W em ligas do sistema Cr$\mathrm{Ni}$ [7]. O controle do teor de carbono nessas ligas deve ocorrer em função da condutividade térmica.

A estabilidade microestrutural, também, deve ser alcançada em material submetido a ciclos térmicos. Ferro fundido de alto cromo com matriz ferrítica apresenta maior resistência à fadiga térmica do que ligas com matrizes austeníticas e martensíticas e, portanto, maior estabilidade microestrutural [8].

A adição de terras raras e de elementos químicos formadores de carbonetos como o $\mathrm{Nb}$ e Ti propicia a fragmentação dos carbonetos primários em ligas de ferro fundido branco. Por outro lado, a adição de terras raras e de alumínio em ligas de Fe-Cr-C favorece a formação de camada de passivação superficial e, por conseguinte, ao aumento da resistência à degradação química [9]. Em termos de classificação de desempenho de materiais, o principal tipo de avaliação de materiais se dá por determinação da perda de massa de peças após o uso em escala industrial. Os ensaios de desgaste abrasivo e corrosivo são opções para a tomada de decisão mais rápida, podendo ocorrer de forma separada ou por interação dos mecanismos 
de degradação $[7 ; 10]$. Ensaios de fadiga térmica apesar de serem citados para avaliação de materiais para cilindros de laminação [7], não são citados em literatura para avaliação de grelhas. No entanto, pode-se adotar a metodologia de ciclagem térmica aplicada em cilindros de laminação, cabendo a adequação das condições térmicas àquela aplicada em grelhas.

Apesar da fundamentação técnica de que a melhoria do projeto de liga para aplicações industriais, como no caso de grelhas, passa pelo incremento de elementos de liga e, por conseguinte, maior valor agregado ao referido produto, na prática, a análise levando em consideração apenas o custo da liga muitas vezes inviabiliza tal iniciativa. Neste caso, a melhor abordagem se dá pela análise de custo/benefício. O custo/benefício pode ser avaliado pelo relacionamento entre o custo da liga e o desempenho da peça. Desta forma, a redução de gastos com reposição de grelhas na sinterização pode ser obtida, mesmo em materiais com maior custo da liga [11].

\section{MATERIAIS E MÉTODOS}

Cinco projetos alternativos de ligas (L1 - L5) foram avaliados, com variações da composição química conforme a tabela 1. Para os elementos químicos $\mathrm{Si}, \mathrm{Nb}$, Terras raras e Al apenas um nível de variação da composição química foi avaliada em relação à liga de referência (LR). Dois níveis de variação de composição química foram avaliados para $\mathrm{Cr}$, Mo, W e Ni e três níveis para C e Mn.

Tabela 1. Variação da composição química dos projetos alternativos de liga para grelhas, comparativamente ao projeto de liga atual adotado na Usiminas.

\begin{tabular}{|c|c|c|c|c|c|c|c|c|c|c|c|c|c|}
\hline $\mathrm{Li}$ & $g a$ & c & $\mathrm{Cr}$ & Si & & Mn & & Mo & $w$ & $\mathrm{Ni}$ & $\mathrm{Nb}$ & $\begin{array}{l}\text { Terras } \\
\text { Raras }\end{array}$ & Al \\
\hline L & R & 1,2 & 24,0 & 0,7 & & 0,6 & & - & - & 1,1 & - & - & - \\
\hline L & 1 & $\uparrow$ & $\uparrow$ & $\uparrow \uparrow$ & & $\uparrow \uparrow$ & & $\uparrow \uparrow$ & $\uparrow$ & $\downarrow$ & | & $\uparrow$ & $\uparrow \uparrow \uparrow$ \\
\hline & 2 & $\uparrow \uparrow$ & $\uparrow$ & $\uparrow \uparrow$ & & $\uparrow \uparrow$ & & $\uparrow \uparrow$ & $\uparrow \uparrow$ & $\downarrow$ & I & $\uparrow$ & $\uparrow \uparrow \uparrow$ \\
\hline & 3 & $\uparrow$ & $\uparrow$ & $\uparrow \uparrow$ & & $\uparrow \uparrow \uparrow$ & & I & I & $\uparrow \uparrow$ & | & | & | \\
\hline & 4 & $\uparrow$ & $\uparrow$ & $\uparrow \uparrow$ & & $\uparrow$ & & $\uparrow$ & I & | & I & I & | \\
\hline & 5 & $\uparrow \uparrow \uparrow$ & $\downarrow \downarrow$ & I & & I & & $\uparrow \uparrow$ & 1 & I & $\uparrow$ & 1 & I \\
\hline \multicolumn{14}{|c|}{ LEGENDA } \\
\hline \multicolumn{3}{|c|}{ Equivalente } & $\downarrow$ & Abaixo & $\downarrow \downarrow$ & $\begin{array}{l}\text { Muito } \\
\text { abaixo }\end{array}$ & $\uparrow$ & Acima & $\uparrow \uparrow$ & \multicolumn{2}{|c|}{$\begin{array}{l}\text { Muito } \\
\text { acima }\end{array}$} & $\uparrow \uparrow \uparrow$ & $\begin{array}{c}\text { Extremamente } \\
\text { acima }\end{array}$ \\
\hline
\end{tabular}

Blocos fundidos em moldes de areia e em forno de fusão por indução foram utilizados para a confecção de corpos de prova dos ensaios de desgaste abrasivo, oxidação cíclica e de fadiga térmica. Para o ensaio de desgaste, as dimensões dos corpos de prova foram de $76 \mathrm{~mm} \times 25 \mathrm{~mm} \times 13 \mathrm{~mm}$, enquanto para o ensaio de desgaste corrosivo foram no formato de cubos com $25 \mathrm{~mm}^{3}$. Os corpos de prova para o ensaio de fadiga térmica foram confeccionados numa geometria conjugada de tronco de cone e cilindro, com extensão de $19 \mathrm{~mm}$ e diâmetro de $25 \mathrm{~mm}$, visando impor elevado gradiente térmico na sua superfície periférica. Os ciclos térmicos do ensaio de oxidação cíclica e de fadiga térmica basearam-se em perfis térmicos obtidos por monitoramento térmico de grelhas em uso industrial.

O ensaio de desgaste abrasivo foi realizado em equipamento do tipo Roda de Borracha, segundo método E da norma ASTM G65 [12], utilizando abrasivo de sílica com grau de finura AFS 50 , em corpos de prova previamente tratados termicamente 
numa temperatura de $750^{\circ} \mathrm{C}$ por 100 horas, seguido de resfriamento lento no interior do forno em atmosfera oxidante. A perda de massa após o ensaio de desgaste foi determinada utilizando balança de precisão de $0,00001 \mathrm{~g} \mathrm{e}$, posteriormente, transformada para volume removido.

O ensaio de oxidação cíclica foi realizado em equipamento desenvolvido no Centro de Pesquisa e Desenvolvimento, no qual foram avaliadas simultaneamente as cinco ligas com perfis térmicos equivalentes àqueles impostos nas grelhas em escala industrial, com temperaturas inicial de $400^{\circ} \mathrm{C}$ e máxima de $750^{\circ} \mathrm{C}$, em intervalo de tempo de 20 minutos, totalizando 1100 ciclos térmicos. O aquecimento foi realizado pela queima de gás de coqueria (COG - Coke Oven Gas) e o controle do perfil térmico a partir de monitoramento da temperatura por termopares introduzidos no interior do corpo de prova.

O ensaio de fadiga térmica foi realizado em equipamento desenvolvido pelo Instituto de Pesquisas Tecnológicas do Estado de São Paulo, com perfil térmico equivalente ao utilizado no ensaio de oxidação cíclica, utilizando-se um intervalo de tempo de cinco minutos, desde o aquecimento até o final do resfriamento do corpo de prova, totalizando 200 ciclos térmicos por liga avaliada. Em função dos resultados obtidos no ensaio de desgaste abrasivo, apenas as ligas L2 e L3 foram avaliadas nesse ensaio.

A caracterização microestrutural das ligas no estado bruto de fundição e após o ensaio de oxidação cíclica foi realizada a partir de observações por microscopia eletrônica de varredura e por espectroscopia por energia dispersiva.

O nível de endurecimento das ligas alternativas no estado bruto de fundição em comparação com a liga de referência foi determinado a partir do teste de dureza Vickers, tendo em vista a importância dessa propriedade no entendimento da resistência ao desgaste de materiais de ferro fundido de alto cromo.

O efeito da expansão térmica das grelhas em função do tipo de material foi avaliado a partir da determinação do coeficiente de expansão térmica no equipamento de dilatometria, modelo DIL805 e versão 70.

A determinação do custo/benefício das ligas avaliadas se deu a partir do custo da matéria prima e do volume removido. O custo da liga foi baseado na quantidade adicionada e no preço da matéria-prima, enquanto o volume removido foi obtido no ensaio de desgaste abrasivo. As expressões a seguir foram adotadas para determinar o custo/benefício de cada liga avaliada.

$$
\text { Custo / benefício da liga } X=\frac{\text { custo relativo da liga } X}{\text { custo relativo da liga referência }} \text {, }
$$

Por sua vez:

$$
\text { Custo relativo da liga }=\text { custo relativo da liga } \cdot \frac{\text { Desgaste abrasivo da liga }\left[\mathrm{mm}^{3}\right]}{\text { Desgaste abrasivo da liga referência }\left[\mathrm{mm}^{3}\right]} \text {, }
$$

Considerando as condições do ensaio de desgaste abrasivo como representativas, pode-se estimar a vida útil das ligas alternativas segundo a expressão a seguir.

$$
\text { Vida útil estimada da liga } X=\frac{\text { Vida útil da liga referência }}{\text { relação de desgaste abrasivo }\left(2^{\circ} \text { termo da equação } 2\right)} \text {, }
$$

A vida útil das grelhas de referência foi considerada como 18 meses. 


\section{RESULTADOS E DISCUSSÃO}

\subsection{Caracterização da Degradação das Ligas Alternativas}

O desgaste abrasivo foi avaliado em termos de volume removido a partir da perda de massa em seis experimentos por liga e do desgaste corrosivo em termos de profundidade da camada degradada por corpo de prova, avaliado em oito medições, conforme a tabela 2.

Tabela 2. Desgaste abrasivo e desgaste corrosivo a partir de ensaios de Roda de Borracha e Oxidação Cíclica, respectivamente, em cinco projetos de liga.

\begin{tabular}{|c|c|c|c|c|c|c|c|}
\hline & Liga & LR & L1 & L2 & L3 & L4 & L5 \\
\hline $\begin{array}{c}\text { Desgaste } \\
\text { abrasivo } \\
\left(\mathrm{mm}^{3}\right)\end{array}$ & Média & 95,0 & 48,4 & 28,4 & 94,9 & 61,6 & 56,6 \\
\hline & Desvio padrão & 9,98 & 11,99 & 4,12 & 11,37 & 11,43 & 7,12 \\
\hline $\begin{array}{c}\text { Oxidação } \\
\text { cíclica }\end{array}$ & Média & 79,1 & 11,7 & 7,3 & 46,5 & 84,4 & 151,1 \\
\hline$(\mu \mathrm{m})$ & Desvio padrão & 4,01 & 1,60 & 1,58 & 2,65 & 3,97 & 4,74 \\
\hline
\end{tabular}

A partir de análise de variância de fator único e nível de confiança de $95 \%$ constatou-se que médias de volume removido por desgaste abrasivo e de profundidade de camada de corrosão entre as ligas avaliadas apresentaram diferenças significativas [13]. As ligas L1 e L2 se destacaram em termos de menor índice de desgaste abrasivo e menor profundidade de camada de corrosão, provavelmente, em função da maior adição de $\mathrm{C}, \mathrm{Cr}$, Mo e W, elementos formadores de carbonetos mais resistentes ao desgaste e mais estáveis em elevadas temperaturas, além de Terras raras e Al, elementos formadores de camada de óxidos mais resistentes.

A liga L5 apresentou o terceiro melhor resultado de resistência ao desgaste abrasivo, porém, a maior profundidade de camada corrosiva, inclusive superior ao resultado da liga de referência.

A maior adição de $\mathrm{Mn}$ e Ni na liga L3 favoreceu a resistência à corrosão a quente, mas prejudicou consideravelmente a resistência ao desgaste. A proposta de formação de uma estrutura austenítica mais estável ao longo do tempo não supriu o efeito da ausência de elementos formadores de carbonetos estáveis em elevadas temperaturas.

$\mathrm{Na}$ figura 2 é mostrado o aspecto dos corpos de prova de três ligas submetidos ao ensaio de fadiga térmica, destacando-se a ausência de trincas superficiais.

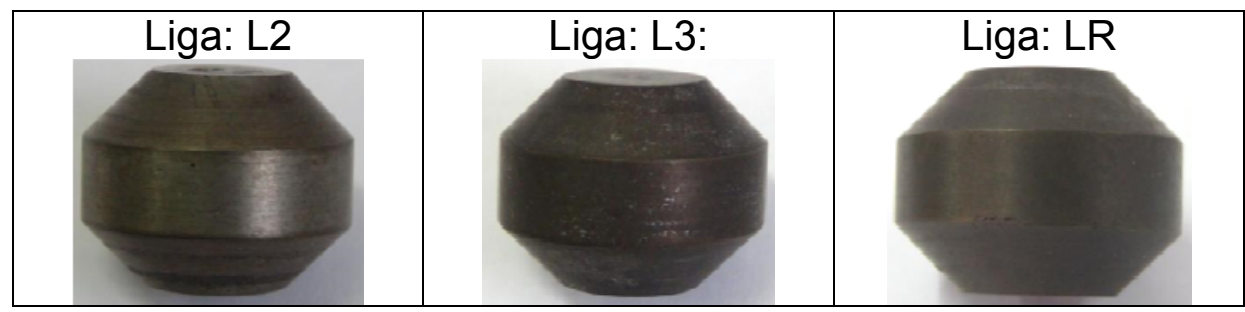

Figura 2. Aspecto dos corpos de prova submetidos ao ensaio de fadiga térmica para as ligas $L 2$ e $L 3$, comparativamente à liga de referência (LR). 
A maior resistência ao desgaste abrasivo e corrosivo das ligas $\mathrm{L} 1$ e $\mathrm{L} 2$ e a ausência de fadiga térmica na liga L2 podem ser atribuídas à maior estabilidade dos carbonetos e maior resistência à corrosão em elevadas temperaturas, além de maior resistência ao desgaste em relação à liga de referência.

\subsection{Características Complementares das Ligas Alternativas}

Os valores médios e de variabilidade da dureza Vickers com carga de $10 \mathrm{kgf}$ e do coeficiente de expansão térmica das ligas avaliadas são mostrados na tabela 3 , comparativamente à liga de referência. A partir de análise de variância de fator único e nível de confiança de $95 \%$ constatou-se que médias de dureza Vickers e de expansão térmica entre as ligas avaliadas, também, apresentaram diferenças significativas. Esses resultados confirmam a importância da sinergia entre os mecanismos de desgaste abrasivo e corrosivo na resistência ao desgaste.

Tabela 3. Dureza Vickers média e coeficiente de expansão térmica das ligas alternativas comparativamente à liga de referência (LR).

\begin{tabular}{|c|c|c|c|c|c|c|c|}
\hline & Liga & LR & L1 & L2 & L3 & L4 & L5 \\
\hline $\begin{array}{c}\text { Dureza } \\
\text { Vickers } \\
\text { 10 kgf } \\
\text { (HV10) }\end{array}$ & Média & 369 & 356 & 475 & 331 & 397 & 471 \\
\hline $\begin{array}{c}\text { Coeficiente } \\
\text { de expansão } \\
\text { térmica } \\
\left(10^{-5} \mathbf{k}^{-1}\right)\end{array}$ & Média & 10,1 & 6,9 & 19,3 & 7,9 & 11,2 & 10,9 \\
\hline & $\mathbf{n}$ & 10 & 10 & 10 & 10 & 10 & 10 \\
\hline
\end{tabular}

No caso da liga L1, o segundo melhor resultado de desgaste abrasivo e corrosivo pode ser atribuído ao efeito de menor endurecimento estrutural e estabilidade dos carbonetos em elevadas temperaturas, em função da menor quantidade de $\mathrm{C}$ e W em relação à liga $L 2$. Na comparação entre os resultados de desgaste abrasivo e o teste de dureza, o desempenho da liga L1 em relação às demais ligas sugere que a dureza do material não foi a única característica que favoreceu o aumento da resistência ao desgaste. Provavelmente, esse resultado possa ser justificado pela maior resistência à corrosão a quente e as características morfológicas e químicas dos carbonetos da liga L1 em relação às demais ligas com dureza equivalente (LR, L3 e L4).

A liga L5, apresentando dureza do material muito próximo do valor da liga L2, deveria apresentar uma resistência ao desgaste maior do que aquele obtido. No entanto, essa liga apresentou uma profundidade elevada de produto corrosivo, o que, provavelmente, contribuiu para o aumento do desgaste abrasivo. A diminuição do teor de $\mathrm{Cr}$ em relação às demais ligas pode ter contribuído para a diminuição da resistência à corrosão dessa liga.

A dureza do material ainda tem uma contribuição destacada na resistência ao desgaste das ligas de ferro fundido de alto cromo, como se pode perceber nos resultados da liga L3. Esta liga apresentou a menor dureza e o maior índice de desgaste abrasivo, mesmo com uma profundidade intermediária de produto corrosivo. 
Quanto às características microestruturais mostradas na tabela 4, a presença de carbonetos de $\mathrm{M}_{7} \mathrm{C}_{3}$ e $\mathrm{NbC}$ nas ligas 2 e 5 pode ser apontada como um aspecto fundamental para a obtenção de menores índices de desgaste abrasivo. Neste caso, a maior densidade superficial, a distribuição e a formação dos carbonetos descontínua protegem a matriz da degradação dos abrasivos, apesar de a matriz ser ferrítica. No caso das ligas de referência e da liga L3, a formação de carbonetos contínuos e a sua menor densidade superficial desses compostos favoreceram a exposição da matriz ao efeito de desgaste abrasivo. Além disso, a maior instabilidade térmica pode ter contribuído para a facilitação da ruptura da camada de óxidos.

Tabela 4. Aspecto microestrutural no estado bruto de fundição das ligas alternativas, comparativamente à liga de referência (LR).

\begin{tabular}{|c|c|c|}
\hline Liga & Matriz & Carbonetos primários \\
\hline LR & $\begin{array}{c}\text { Ferrita delta }(\delta) \mathrm{e} \\
\text { austenita }(\gamma)\end{array}$ & $\mathrm{M}_{7} \mathrm{C}_{3}$ contínuos \\
\hline L1 & Ferrita $(\alpha)$ & $\mathrm{M}_{7} \mathrm{C}_{3}$ contínuos \\
\hline L2 & Ferrita $(\alpha)+\mathrm{NbC}$ & $\mathrm{M}_{7} \mathrm{C}_{3}$ dispersos \\
\hline L3 & Ferrita $(\alpha)$ e austenita $(\gamma)$ & $\mathrm{M}_{7} \mathrm{C}_{3}$ contínuos \\
\hline L4 & Ferrita $(\mathrm{a})$ & $\mathrm{M}_{7} \mathrm{C}_{3}$ semicontínuos \\
\hline L5 & Ferrita $(\mathrm{a})+\mathrm{NbC}$ & $\begin{array}{c}\mathrm{M}_{7} \mathrm{C}_{3} \text { contínuos } \mathrm{e} \\
\text { grosseiros }\end{array}$ \\
\hline
\end{tabular}

\subsection{Perspectivas de Desempenho das Ligas Alternativas}

Considerando as estimativas de custo/benefício e de vida útil segundo o valor médio do volume removido por desgaste abrasivo, pode-se dizer que as ligas 2 e 5 se destacaram em relação às demais ligas alternativas, conforme a figura 3 . Sob o ponto de vista de custo/benefício, essas ligas seriam apontadas como as mais economicamente viáveis. A liga L2 apresentou a melhor perspectiva de desempenho em substituição à liga de referência, mesmo apresentando um maior custo da liga, com aumento da vida útil da ordem de três vezes. Isto implica em possibilidade de diminuição das paradas operacionais para troca de grelhas ou setores de grelhas e, por conseguinte, o aumento da produtividade das máquinas de sinterização.

No caso das ligas $L 1$ e $L 3$, o balanço de custo da liga e resistência ao desgaste tornaram tais ligas como aquelas com maior custo/benefício, inviabilizando, a princípio, a sua utilização. No caso da liga L1, apesar da sua semelhança com a liga L2, a menor adição de $C$ pode ter contribuído para a diminuição da resistência ao desgaste. $\mathrm{A}$ adequação do teor de $\mathrm{C}$ não deve alterar significativamente $\mathrm{o}$ custo desta liga, mas pode melhorar a sua resistência ao desgaste. 


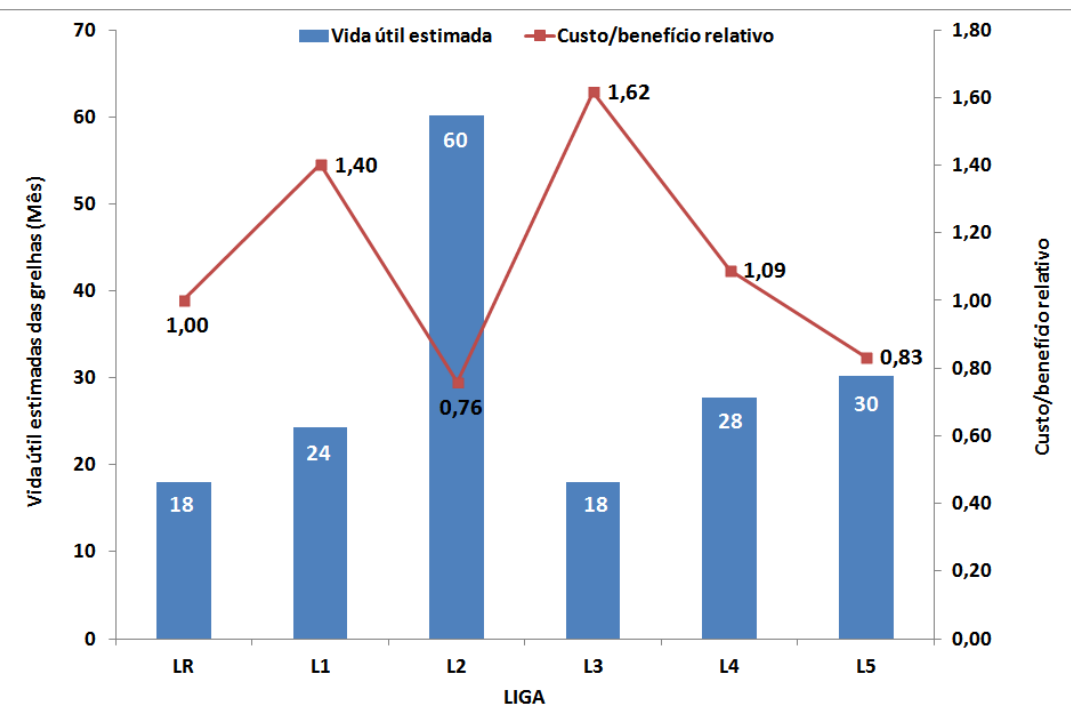

Figura 3. Estimativas de custo/benefício relativo e de vida útil das ligas alternativas a partir do valor médio de volume removido por desgaste abrasivo, comparativamente à liga de referência.

As estratégias menos radicais representadas pelas ligas L4 e L5 podem ser opções para momentos específicos em que o custo da liga tenha prioridade, pelo menos a curto ou médio prazo, na decisão de melhoria de desempenho das grelhas. Isto se deve ao fato do incremento de apenas $9 \%$ ou de redução de $17 \%$ no custo/benefício destas ligas, respectivamente, porém um incremento de sua vida útil da ordem de $55 \%$ e $70 \%$ em relação à liga de referência.

De forma geral, pode-se dizer que a metodologia proposta neste trabalho para a escolha de materiais para as grelhas de sinterização a partir da interação do custo da liga e do seu desempenho, retratada pela análise do custo/benefício, parece ser útil na tomada dessa decisão, pois fornece pelo menos três frentes de atuação: (i) adoção de custo benefício viável comparativamente à referência e em função do aumento da vida útil; (ii) inviabilização de opções de elevado custo/benefício; (iii) adoção de opções, em função de menor custo da liga, a serem utilizadas em momentos estratégicos.

\section{CONCLUSÃO}

$\mathrm{Na}$ avaliação dos mecanismos de desgaste abrasivo, a alternativa de liga (liga L2) com adição de $\mathrm{W}$, Mo, Al, Terras raras e maior teor de $\mathrm{C}$ apresentou menor desgaste abrasivo em relação às demais ligas, com perspectiva de aumento da vida útil para esse tipo de componente mecânico da ordem de três vezes em relação à condição atual.

Em termos de degradação por corrosão a quente, a liga L2, também, apresentou menor profundidade da camada de produto corrosivo.

$\mathrm{Na}$ avaliação de fadiga térmica nenhuma das ligas avaliadas apresentou este tipo de degradação.

A maior resistência ao desgaste e à corrosão a quente da liga L2 pode ser atribuída à maior estabilidade dos carbonetos, à maior resistência à corrosão a quente e à formação de camada de óxidos mais estável em elevadas temperaturas.

O desempenho de outros projetos de liga pode ser destacado, como, por exemplo, o caso das ligas L4 e L5, com incremento nos teores de $\mathrm{C}$ e de elementos químicos formadores de carbonetos secundários (Mo e $\mathrm{Nb}$ ) em relação à liga de referência. Estas alternativas apresentaram menor impacto no custo da liga em relação à 
liga L2 e podem ser utilizadas em momentos específicos em que o custo da liga tenha prioridade na tomada de decisão de substituição de liga.

A alternativa de liga com maior adição de Mn e Ni (liga L3) se tornou inviável, em função do maior custo/benefício e sem expectativa de melhoria da vida útil desse componente mecânico.

A metodologia de escolha de ligas alternativas com expectativa de melhoria da vida útil de grelhas de sinterização apresentada neste trabalho está sendo validada em escala industrial na Usiminas, porém, não foi o foco deste trabalho. Futuros trabalhos avaliarão este aspecto.

\section{REFERÊNCIAS}

1 Ball, D F; Dartnell, J; Davison, J; Grieve, A; Wild, R. Agglomeration of Iron Ores Chapter 5: Modern Aglomeration Practice. Edition: HEB - Heinemann Education Books Limited London. 1973.

2 Rossi, C S. Caracterização dos Materiais Utilizados nas Barras de Grelhas das Linhas de Sinterização da CSN. XVII Seminário ABM: Fusão, Refino e Solidificação dos Aços. 1996.

3 Leyva, C A L; Moysés, R. R.; Macedo, M. C. S.. Estudo Comparativo de Materiais para Barras de Grelha para Usinas de Sinterização. 55 Congresso ABM. 2000.

4 Albertin, E; Neto, F B; Teixeira, I O. Otimização do Tratamento Térmico de ferros Fundidos Brancos Utilizando Termodinâmica Computacional. Tecnol. Metal. Mater. Miner., São Paulo, v. 8, n4, 2011.

5 Xing, J D, Gao, Y M, Wang, E Z, Bao, C G. Effect of phase stability on the wear resistance of white cast iron at $800 \circ \mathrm{C}$. Wear 252. 2002.

6 Baotong, L, Jingli, L, Chiovelli, S. Corrosion and Wear Resistance of Chrome White Irons - A Correlation to Their Composition and Microstructure. Metallurgical and Materials Transactions. Volume 37A. October. 2006

7 Bicalho, R M; Nascimento, F M P; Oliveira, J G; Vieira, N; Braga, R N B; Borges, W O; Souza, V Q; Santos, F R G. Desenvolvimento da Qualidade da Barra de Grelha da Sinterização da Belgo-Mineira em Parceria com a Fundição da Acesita. XXX Seminário de Redução de Ferro. 1999.

8 Beleyakova, P. E; Garber, M. E; Rozhkova, E. V. Physical Properties of White Chromium Cast Irons. 1975

9 Komarov, O S; Sadovskii, V M; Urbanovich, N I; Lifshits, G F. Thermal Stability of High-Chromium Cast Iron. Metal Science and Heat Treatment, vol. 44, n 1-2. 2002.

10 Zhang, T; Li, D Y. Effect of alloying yttrium on corrosion-erosion behavior of $27 \mathrm{Cr}$ cast white iron in different corrosive slurries. Materials Science and Engineering. A325. 2002

11 Lima, E C; Nascimento, F M P, Heep, H; Milanez, J J; Toríbio, N M. Desenvolvimento da Qualidade do Produto de Barra de Grelha e seu Reflexo nas Pelotizações Brasileiras. 1982.

12 American Society for Testing and Materials. ASTM G65: Standard Test Method for Measuring Abrasion Using the Dry Sand/Rubber Wheel Apparatus. 2004.

13 Triola, M F. Introdução à Estatística. Sétima Edição. Editora LTC - Livros Técnicos e Científicos Editora S.A.. 1999. 